\title{
A produção escrita de aprendizes de português como língua estrangeira adicional: a referenciação como recurso de processamento sociocognitivo
}

\author{
Lucia ROTTAVA \\ Universidade Federal do Rio Grande do Sul (UFRGS) \\ luciarottava@yahoo.com.br
}

\section{Resumo}

Este texto focaliza a referenciação na produção escrita de aprendizes de português como língua estrangeira adicional. A referenciação consiste na construção e na reconstrução de objetos de discurso, produto resultante da atividade cognitiva e interativa. Dentre as formas de interação, a produção escrita é um processo interativo em virtude de os sentidos serem construídos pela interação escritorleitor e texto em processos complexos e multifacetados que envolvem experiências elou conhecimentos anteriores, além do propósito discursivo do(s) interlocutor(es). Portanto, o texto é resultado de uma ação "em construção" realizada pelo uso da linguagem. Os dados para análise são extraídos de tarefas de produção escrita realizadas como parte das aulas de português como língua estrangeira e com sujeitos de diferentes níveis de proficiência, aprendizes de português como língua estrangeira adicional. Os resultados revelam o processamento textual dos aprendizes e suas especificidades decorrentes do nível de proficiência e das exigências da natureza e temática da tarefa.

Palavras-chave: referenciação; processamento sociocognitivo; português como língua estrangeira adicional

1 Doutora em Linguística Aplicada pela UNICAMP. Professora do Departamento de Letras Clássicas e Vernáculas -DECLAVE - do Instituto de Letras da Universidade Federal do Rio Grande do Sul UFRGS. 


\begin{abstract}
This article discusses referentiation in texts written by learners of Portuguese as an additional foreign language. Referentiation consists of construction and reconstruction of discourse objects, a product that results from cognitive and interactive activity. Among forms of interaction, written production is an interactive process as meanings derive from the interaction between writer/reader and text in complex and multifaceted experiences that involve prior experiences and/or knowledge, besides the interlocutor's discursive purpose. Therefore, the text is the result of an action 'under construction' made possible through the use of language. Data for this article come from written production developed in classes of Portuguese as a foreign language. The findings reveal learners' textual processing and its peculiarities resulting from the learners' proficiency levels and the requirements of the type and theme of the specified task.
\end{abstract}

Keywords: referentiation; socio-cognitive process; Portuguese as an additional foreign language

\title{
1. Introdução
}

Compreende-se, genericamente, a referenciação como um processo de operacionalização da linguagem ${ }^{2}$ para garantir a continuidade de sentido de um texto. Dar continuidade a um texto é uma atividade que vai além do uso de recursos linguísticos, pois envolve processamento interativo entre sujeito-escritor e texto que é situado socialmente.

Entender a referenciação como produto da atividade interativa e sociocognitiva e decorrente da construção e da reconstrução de objetos de discurso é uma discussão recente que contempla o uso de linguagem $(\mathrm{KOCH}$, 1999; MONDADA; DUBOIS, 2003; MONDADA, 2005; ZAMPONI, 2005; BENTES; RIO, 2005). É recente porque a referenciação não apenas diz respeito ao processamento linguístico-gramatical em frases isoladas, mas

2 Operacionalização da linguagem, de uma perspectiva sociointeracional, consiste de um trabalho sociocognitivo e social com a própria linguagem que supõe interação, visto sua natureza heterogênea, histórica e socialmente constituída. Nesse sentido, a construção da refererenciação na produção escrita, ilustrada neste artigo, requer negociação no discurso, que resulta na construção de referentes em textos escritos por sujeitos aprendizes de uma LE-adicional. 
também ao processamento sociocognitivo, cujos dados são constituídos por registros advindos de diversas formas de interação. Investigar recursos de referenciação é relevante porque os objetos de discursos são construídos e reconstruídos no interior do próprio discurso, de acordo com a percepção de mundo, das crenças e das experiências prévias dos sujeitos como aprendizes de uma língua estrangeira (LE), assim como suas atitudes e propósitos comunicativos. Em se tratando de LE, a reflexão sobre referenciação indica como o conhecimento de LEs pode ativar, na interação com o texto, outros conhecimentos necessários à progressão dos sentidos de um texto.

Português LE-adicional tem sido um termo recorrentemente usado para referir-se aos contextos nos quais a aprendizagem de português é mais uma língua dentre outras que o aprendiz está adquirindo ou usa em algumas situações de interação no seu cotidiano. Em função da expansão da língua portuguesa por motivos políticos, econômicos e culturais, a demanda de interessados por motivos diversos também se tem expandido (ROTTAVA; SILVA, 2011). Esse aumento significa que falantes de línguas diversas e com experiências de aprendizagem prévias com outras LEs têm mudado a configuração do ensino e da pesquisa. Atualmente, o português pode ser considerado uma LE-adicional, pois, como Rottava (2009) observou, aprender português LE refere-se "a todas as línguas além da LE/L2 sem dar preferência a alguma em particular" (p. 85), e ao fato de os aprendizes já terem tido contato com outros sistemas linguísticos, caracterizando-lhes como aprendizes mais experientes em relação à aprendizagem de línguas.

Em contexto de português LE-adicional, a produção escrita desses aprendizes pode permitir que se compreenda o processamento sociocognitivo em função do modo como eles constroem e reconstroem objetos de discurso revelados pela interação com o texto, pelo uso da linguagem decorrente de experiências prévias com outras LEs, pela proficiência na LE e pelas exigências da natureza e da temática da tarefa. Nesse contexto, portanto, a produção escrita é concebida como um texto situado socialmente (CONNOR, 2004), isso porque para que sua produção se concretize é necessário que se considerem interlocutores, propósitos, 
nível de adequação, expectativas e normas do discurso de uma comunidade discursiva em particular, ou seja, uma atividade social situada culturalmente.

Diante do exposto, o objetivo deste artigo é analisar processos de referenciação na produção escrita de aprendizes de português LE-adicional, buscando compreender: (i) quais as estratégias de referenciação usadas por aprendizes em suas produções escritas; (ii) o que essas estratégias revelam em termos de processamento sociocognitivo desses aprendizes.

Para tanto, este texto está organizado em quatro seções. Na primeira, são trazidas discussões teóricas relativas ao conceito de referenciação; na segunda, será descrito o desenho metodológico do estudo; na terceira, serão feitas as análises em termos das estratégias de referenciação observadas; finalmente, serão feitas algumas considerações finais.

\section{Referenciação - uma atividade de processamento sociocognitivo}

O conceito de referenciação é advindo da Linguística Textual, que, em princípio, dizia respeito aos recursos de processamento linguísticogramatical de frases isoladas. Esse processamento, denominado referência, envolve dois elementos principais: referente - a forma retomada pelo elemento coesivo, e forma remissiva - a interpretação requer um referente, e os elementos referenciais não podem ser interpretados por si próprios, mas precisam estar relacionados a outros elementos no texto para serem compreendidos. Subjacente a esse conceito, a base teórica concebia a referenciação como representação extensional de objetos do mundo real. Os referentes apresentavam uma representação triádica do signo linguístico: significante/ significado/ objeto, em termos saussureanos.

No entanto, na interação, novos referentes são introduzidos no texto de formas distintas, podendo estar ou não literalmente presentes, pois, em certas condições, as sequências linguísticas podem ser associadas a certos segmentos da realidade que supostamente designam (MILNER, 2003). 
Esses segmentos da realidade revelam o modo como a língua refere 0 mundo, porque as escolhas dos recursos para a introdução e a manutenção da referência resultam das relações que os sujeitos mantêm no meio social em que vivem.

Ao considerar como a língua refere o mundo, a visão de referenciação deixa de ser um problema estritamente linguístico e passa a ser concebida como um fenômeno que concerne simultaneamente à cognição e aos usos da linguagem em sociedade. Essa visão alinha-se ao desenvolvimento das ciências cognitivas na década de 1990, que passou a tratar do termo referenciação "como objeto do discurso, construído numa situação de interação sociocognitiva” (LIMA, 2005).

Desse modo, na interação, oral ou escrita, os sujeitos-aprendizes recorrem ao conhecimento linguístico que têm à sua disposição como resultado da aprendizagem de uma $\mathrm{LE}$ e do contexto multilíngue onde convivem e, por conseguinte, as escolhas representam o "querer-dizer" do escritor. Por sua vez, as interações sempre se dão em um tempo e em um espaço (ZAMPONI, 2005) e, nesse sentido, trata-se de atividades situadas colaborativamente. Nas palavras de Zamponi (2005):

[...] todo o ato de referência não se dá fora do tempo, do espaço e de uma relação interlocutivainterativa. É um ato sempre situado e envolve uma operação colaborativa dos parceiros da interação, que constroem os referentes no e pelo discurso, atividade linguística e sociocognitiva ligada, acima de tudo, à interação e à intersubjetividade (p. 173).

Esse olhar para a referenciação muda também o modo como é definido o objeto de análise. Para Mondada (2005), o objeto de análise diz respeito às práticas referenciais manifestadas na interação. A autora inclui não somente as práticas linguageiras, mas também as práticas gestuais, movimentos no espaço e orientação do olhar. Os referentes, nessas práticas, são instaurados na realização e no desenrolar da atividade referencial pela maneira mesmo como esta é reconhecidamente organizada (p. 12). 
Buscando entender como essas práticas revelam o processamento sociocognitivo de seus usuários na construção e na reconstrução dos sentidos do texto, Mondada (2005), Zamponi (2005) e Bentes e Rio (2005) investigaram como elas são concretizadas na interação.

Mondada (2005) analisa um recurso formal you see, extraído de interações entre cirurgiões durante seu trabalho em uma sala de operações. O uso desse recurso, de acordo com a autora, permite revisitar o problema da referência elou topicalidade. $\mathrm{O}$ foco de análise é sobre o tópico e a dêixis, remissões interessantes à visibilidade dos objetos. A autora utiliza-se de gravações em vídeo, salientando que o uso desse recurso possibilita "uma reflexão sobre a referenciação a propriedades visuais no discurso e na língua em interação" (p.13). Dentre os resultados elencados pela autora, o apelo à visão (manifestado, sobretudo, por you see) parece ter se tornado no contexto um dispositivo complexo de produção referencial em que a fala, o gesto, o instrumento cirúrgico e a disposição do espaço anatômico por meio das pinças contribuem para a realização da referência (p. 25).

Por sua vez, Zamponi (2005) analisa estratégias de reformulação em gênero de popularização da ciência, destacando que se trata de textos resultantes de um processo de recontextualização do conhecimento científico, pois, inicialmente, são resultados de pesquisas publicadas em periódicos especializados. Ao ser recontextualizado esse conhecimento, as reformulações apresentam uma expressão referencial e uma espécie de retomada, construídas intencionalmente para caracterizar de modo retrospectivo uma expressão que pode estar ausente do universo do conhecimento do leitor. Isso ocorre, de acordo com os resultados, porque "as reformulações são estratégias do escritor para antecipar dificuldades, atitude de que depende o sucesso da construção referencial” (p. 189).

Finalmente, Bentes e Rio (2005) investigam a construção conjunta da referência em uma entrevista semimonitorada com jovens universitários. $\mathrm{O}$ objetivo foi 
[...] mostrar como as práticas referenciais dos sujeitos neste contexto encontram-se intimamente relacionadas ao contexto imediato (objetivos da interação, relacionamento entre os sujeitos, estruturas de participação dos falantes), à maneira pela qual os referentes são mostradosintroduzidos e a certos recursos não verbais mobilizados pelos sujeitos durante as atividades de recontar a história e de fazer comentários sobre a narrativa assistida (p. 267).

Os resultados, de acordo com as autoras, "contribuem fortemente para a concepção de que as práticas de referenciação são, em contexto de interação face a face, multimodais ${ }^{3}$ (são práticas de raciocínio, de reconhecimento perceptivo, de leitura visual), assim como a construção da referência nestes contextos é feita com base em ancoragem de natureza audiovisual.

Isto posto, a análise dos recursos de referenciação presentes em produções escritas de aprendizes de português LE-adicional será baseada nas estratégias de referenciação descritas por Koch (2004, p. 64), quais sejam: (a) introduçãoconstrução: um "objeto" até então não mencionado é introduzido no texto de modo que a expressão linguística que o representa é posta em foco, ficando esse "objeto" saliente no modelo textual; (b) retomadareativação: um "objeto" já presente no texto é reativado por meio de uma força referencial de modo que o objeto-de-discurso permaneça em foco; (c) desfocalização: um novo objeto-de-discurso é introduzido, passando a ocupar a posição focal. O objeto retirado de foco, contudo, permanece em estado de ativação parcial (standby), ou seja, ele continua disponível para a utilização imediata sempre que necessário.

Com base, portanto, nessas estratégias, pode-se entender melhor a atividade cognitiva e interativa dos sujeitos-escritores, uma vez que a referenciação não preexiste a essa atividade, mas é produto dela.

3 De acordo com Mondada (2005), práticas multimodais "obrigam a linguística a não se limitar a dar conta de atividade dos interlocutores que seriam exclusivamente verbais e, assim, relegar os outros processos ao domínio da cognição, mas significa levar em consideração as situações - numerosas - em que a palavra está imbricada na ação não verbal, na materialidade do contexto e na manipulação de objetos" (p. 15-16). 


\section{Desenho do estudo}

Português LE-adicional é oferecido por uma universidade britânica como parte do um curso de bacharelado. No ano letivo de 20082009, foram oferecidos seis níveis de português, consistindo cada nível de 120 h/a durante um ano acadêmico. O total das horas é dividido em uma aula por semana de $3 \mathrm{~h} / \mathrm{a}$ cada.

Os participantes são aprendizes de português LE-adicional. Os dados são provenientes de contexto de sala de aula, coletados no ano letivo 20082009. De um total de 13 participantes, sete são femininos e seis, masculinos, com idade média variando entre 26 e 44 anos, predominando a idade de 30 anos, conforme Quadro 1:

Quadro 1. Perfil dos participantes

\begin{tabular}{|c|c|c|}
\hline Aprendiz & LM & LE/s \\
\hline \multicolumn{3}{|c|}{ Grupo 4} \\
\hline $4 \mathrm{M}$ & inglês & francês \\
\hline $4 \mathrm{~A}$ & inglês & espanhol \\
\hline $4 \mathrm{~S}$ & estoniano & $\begin{array}{c}\text { inglês } \\
\text { espanhol }\end{array}$ \\
\hline $4 \mathrm{~L}$ & eslovaco & inglês \\
\hline $4 \mathrm{G}$ & italiano & $\begin{array}{c}\text { inglês } \\
\text { espanhol }\end{array}$ \\
\hline $4 \mathrm{~F}$ & inglês & francês \\
\hline $4 \mathrm{D}$ & inglês & francês \\
\hline $4 \mathrm{C}$ & francês & $\begin{array}{c}\text { inglês } \\
\text { espanhol }\end{array}$ \\
\hline $4 \mathrm{Gr}$ & inglês & $\begin{array}{c}\text { francês } \\
\text { espanhol }\end{array}$ \\
\hline
\end{tabular}




\begin{tabular}{|c|c|c|}
\hline \multicolumn{3}{|c|}{ Grupo 5} \\
\hline $5 \mathrm{P}$ & espanhol & inglês \\
\hline $5 \mathrm{~S}$ & holandês & $\begin{array}{l}\text { alemão } \\
\text { inglês } \\
\text { francês } \\
\text { espanhol }\end{array}$ \\
\hline $5 \mathrm{D}$ & inglês & francês \\
\hline $5 \mathrm{St}$ & espanhol & inglês \\
\hline
\end{tabular}

Todos os participantes usam ao menos uma LE em casa, com amigos, no trabalho ou em outros contextos, e, dentre elas, o português. A maioria, no entanto, usa o português no curso e com amigos, e o tempo de estudo desta língua varia de um a dois anos. Além disso, eles afirmam que sabem mais do que uma LE, e, dentre elas, ao menos uma é tipologicamente próxima ao português.

\section{Dados de produção escrita}

Os 13 aprendizes produziram trinta textos com temáticas diversas, com uma variação grande no número de palavras, ou seja, 300 a 1.500 palavras. No entanto, se separados os grupos, o grupo Portuguese $I V$ produziu textos com média de 300 a 400 palavras, e o grupo Portuguese $V$ obteve a média de mil palavras. Alguns alunos produziram mais textos e outros menos. Assim, para minimizar as variáveis, foi feita uma pré-seleção, reduzindo para 20 textos a amostra para este estudo.

Os aprendizes são instados a produzir por escrito, durante o curso, inúmeros textos com temáticas e propósitos distintos. Contudo, tais produções estão ligadas às atividades desenvolvidas em sala de aula e de acordo com a previsão no cronograma das aulas. Portanto, não foi solicitado um texto escrito apenas para fins desta pesquisa. 
Para entender o processo de referenciação na produção escrita de aprendizes de português LE-adicional, é necessário descrever quais estratégias de referenciação foram usadas pelos sujeitos em suas produções escritas, buscando exemplificar padrões de recorrência.

A estratégia recorrente que mantém a unidade do texto e amplia as informações tem sido a retomada de um determinado tópico, que é a operação responsável para a manutenção em foco de objeto-de-discurso previamente introduzido, dando origem às cadeias referenciais, responsáveis pela progressão referencial do texto. A progressão pode realizar-se tanto por meio de recursos de ordem gramatical (pronomes, elipses, numerais, advérbios locativos) como por intermédio de recursos de ordem lexical (reiteração de itens lexicais, sinônimos, hiperônimos, nomes genéricos, expressões nominais, etc.). O exemplo (1) mostra a diversidade de recursos utilizados pelo escritor ao produzir o texto "Festival Folclórico do Boi-Bumbá:

(1) Há mais de 40 anos que o famoso "Festival Folclórico do BoiBumbá" é realizado na cidade de Parintins, no nordeste do Brasil.É uma cidade de 60.000 habitantes, mas sua população triplica no mês de junho, quando uma multidão de turistas chega para participar nos festejos. Em Parintins, Bumba-meu-boi não é somente um festival, mas um concurso entre dois bois - o Boi Garantido (branco com coração vermelha na frente) e o Boi Caprichoso (de cor azul com uma estrala na frente). A apresentação acontece no "Bumbodromo" - um estádio com o formato de uma cabeça de boi estilizada. A competição é feroz, e os cores dos bois são muito importantes. A cidade é dividida em vermelho e azul. Quem torce pelo Boi Garantido recusa usar roupa azul, e vice-versa. As pessoas pintam suas cases de azul ou vermelho. Na verdade, Parintins é o único lugar no mundo inteiro onde a publicidade de Coca Cola é de azul!

A referenciação no exemplo (1) é mantida pela recorrência a expressões nominais definidas, como em "festejos", "um festival", "um concurso entre dois bois", "a apresentação", "a competição", referindo-se a "Festival Folclórico de Boi-Bumbá”. Observa-se que as expressões nominais no trecho iniciam dando um sentido mais geral, com "festejos" com distintas nuances 
até o sentido particularizado, observado nos itens lexicais precedidos de artigos definidos: "a apresentação", "a competição”.

Processamento similar ocorre com o recurso "uma cidade"; a referenciação é mantida por um recurso gramatical que define esse referente: "a cidade", indicando que esse recurso também qualifica "em Parintins" e "Parintins", sempre retomando "cidade de Parintins". Há, portanto, uma combinação de recursos de ordem lexical aos de ordem gramatical. Esses itens lexicais funcionam para ativar conhecimentos pressupostos e partilhados com o(s) interlocutor(es) de traços do referente que o locutor procura ressaltar ou enfatizar de acordo com seus propósitos.

Ainda no exemplo (1), outra estratégia que se observa é a desfocalização dos referentes: "uma cidade" e "festejos", entremeando os sentidos que vêm sendo construídos com o intuito de expandir as informações e criar uma teia de sentidos. É o que acontece com a introdução de um objeto de discurso, desta vez recorrendo a um recurso de ordem gramatical: "quem" e mantido por "as pessoas". Nesse sentido, a desfocalização do que vinha sendo dito completa o querer-dizer do autor do texto. Percebe-se, nesse exemplo, que o sujeito-escritor também atualiza informação de natureza diversa para indicar sua capacidade de lidar com conhecimento de uma LE.

A seleção de um determinado recurso de referenciação para atualizar um sentido no texto revela dados importantes relativos a opiniões e atitudes do sujeito-escritor, como em (2):

(2) Acho que qualquer pessoa concorda comigo que durante alguns anos já os jornais por exemplo não parecem mesmos. Queria dizer quando achar algo interessante para ler por exemplo, vai ter sempre algo ao lado colorido, pode ser antes, depois, na capa, sempre têm. Não são coisinhas informativas, são realmente aí só para que o leitor consuma determinados produtos.

No trecho (2), o recurso lexical "coisinhas informativas" é representado por um sintagma nominal que sumariza o que foi dito anteriormente. Introduz assim um elemento novo, sumarizando (encapsulando) a informação difusa no co-texto. 
Ainda com relação ao exemplo (2), levantam-se algumas hipóteses que dizem algo sobre a proficiência do sujeito-escritor. Se, por um lado, revelaria as crenças do sujeito-escritor em querer dizer algo, por outro, pode ser que o recurso ainda não esteja disponível na LE que está aprendendo. A não disponibilidade de um recurso é representada por objetos de discurso mais genérico, como ilustrado em (3):

(3) Nos e focado vários pontos nos textos, mais antes de mais nada: "As raízes do carácter [...], dá-nos a admiração e aceitação, o desprezo e a recusa.

Podemos encontrar estas duas tendências em qualquer ser humano, independemente da cor, raça, religião e cultura".

Então esta afirmação dos textos quer nos falar da necessidade de nos vivermos em sociedade, de sairmos da zona de conforto, exemplos no texto.

No trecho (3), o escritor parece ter dificuldade em introduzir de maneira precisa o termo de que quer tratar; para tanto coloca "vários pontos nos textos”, mas não deixa claro quais são na continuidade do texto. Para tanto, devido ao fato de perceber que tem dificuldade em manter o referente, sua estratégia é citar trecho do texto lido para indicar a que se refere o sentido que construiu na leitura.

Ainda com relação a aspectos ligados à proficiência na LE, não é simples manter a referenciação de modo que o sentido do texto flua com clareza, como em (4):

(4) A proposta que o simples fato de falar a mesma língua traz aceitação e entendimento, não é corroberado na realidade.

Segundo a reportagem dos brasileiros barrados da entrada no Portugal, não era suficiente falar a mesma língua ou tomar parte da mesma herança. Outros critérios venceram.

Ou ainda, não parece ser uma tarefa simples para o sujeito aprendiz relatar por escrito o que leu em outro texto. A proposta da tarefa consistia no relato do livro de contos de Mia Couto intitulado Cada homem é uma raça. Exemplo: 
(5) Há muitos fatores que contribuiram á crise economica mas é importante que todo mundo aprendem de problemas atuais. Por exemplo, os políticos precisam de controlar mais a setor financeira. Além disso, as pessoas precisam de pensar mais realista sobre as vidas delas.

Retomando o aspecto que trata das atitudes ou das crenças dos sujeitos que perpassam a produção escrita, essa dimensão sociocognitiva pode revelar o modo como são introduzidos novos referentes, quando estes resultam de uma sumarização. Nesse caso, revelam que os sentidos construídos sugerem como está sendo desenvolvida a dimensão cognitiva e social do aprendiz na LE que está aprendendo. Observem os exemplos (6) a (8):

(6) saíram da igreja com o púlpito e o confessionário; alguns móveis iam gritando e blasfemando, outros rezando e silenciosos. A torre incandescente, ardente e quente cresceu e cresceu até atingir o mesmo céu e quase colocaram fogo nas nuvens.

(7) [...] Hospedei-me numa pousada antiga e deteriorada. $\mathrm{O}$ calor intenso daquela tarde havia feito os habitantes desaparecerem das ruas. Procurava um lugar para ficar sossego e revisar umas anotações para um artigo do jornal para o qual trabalhava e num quarto esquecido no primeiro andar com vista para a praça achei uma poltrona que parecia ser o único móvel verdadeiramente antigo na pousada. $\mathrm{O}$ resto dos móveis tinham aquele aspecto triste das coisas que já não são modernas, mas tampouco têm a respeitabilidade por sua vetustez.

(8) Considerando-se certos aspectos de fato pode-se pensar na Oktoberfest como um Carnaval, já que inclui elementos característicos do Carnaval como as fantasias, os desfiles, os carros alegóricos, as festas de clube e de rua e representa um momento em que aquilo que os blumenauenses mais valorizam é incorporado aos desfiles nas ruas, do mesmo modo que acontece no Carnaval. Este modelo, inclusive, parece ser o modelo brasileiro de festa, reproduzindo-se freqüentemente tanto em festas religiosas como em festas profanas.

Os três exemplos anteriores mostram que a introdução de um referente resumitivo é dada pela função que desempenha a anáfora indireta e a 
associativa para manter a referenciação às informações anteriormente presentes no texto. Em outras palavras, a anáfora indireta caracteriza-se pelo fato de não existir no co-texto um antecedente explícito, mas apenas um elemento de relação que se pode denominar âncora e que é decisivo para a interpretação; por sua vez, a anáfora associativa introduz um referente novo no texto por meio da exploração de relações meronímicas, ou seja, todas aquelas em que um dos elementos da relação pode ser considerado, de alguma forma, ingrediente do outro, como em "resto dos móveis" no exemplo (6) e "este modelo" em (8).

Como último exemplo que mostra como os aprendizes de português LE-adicional usam dos recursos de referenciação para manter a temática; observe-se:

(9) Eu acho que as pessoas que controlam a propriedade da mídia tambem controlam o ponto de vista que esta leva. Então a comunicação pode ser manipulada de modo que as mensagens entregadas criem uma influência sutil sobre as pessoas que as recebem. (Há pessoas que usam a expressão 'os persuadores ocultos' como sinónimo de 'mídia'.)

No caso da Italia, o meu país, este assunto encontra-se no dia a dia. O chefe do governo atual (o senhor Silvio Berlusconi) é o proprietário da maioria de canais de televisão, jornais e estações de rádio. A opinião geral é que ele foi eleito graças à influência (uma verdadeira e própria 'lavagem-cerebral') que a mídia controlada por ele fizeram sobre a cidadania italiana durante a campanha eleitoral.

No trecho (9), o sujeito escritor, para referir-se à temática "mídia", desfocaliza-a,introduzindo outros referentes por itens lexicais que permitem ampliar o sentido do texto e, portanto, a teia dos sentidos é mantida pelo uso de "comunicação" por uma designação feita pela recorrência de termo ancorado em "mídia" e "ponto de vista". Ou seja, sempre que um novo objeto-de-discurso é introduzido no texto, com base em algum tipo de associação com elementos já presentes no contexto linguístico (co-texto) ou no contexto sociognitivo, a continuidade é mantida. 


\section{Considerações finais}

As estratégias de referenciação recorrentes nas produções escritas de aprendizes de português LE-adicional indicam aspectos importantes do processamento sociocognitivo desses aprendizes, embora com dados preliminares e relativos a um único contexto.

Observou-se o uso recorrente de recursos de ordem lexical, particularmente com expressões nominais (exemplos 1, 2, e 6 a 9, respectivamente). Complementando os resultados que revelam esse padrão, essa estratégia de referenciação é combinada com o uso de recursos de natureza gramatical; nessas situações de uso, os sujeitos-escritores, inicialmente, mantêm a recorrência temática pelo uso de objetos de discurso de sentido genérico e, na sequência do texto, combinam recursos de natureza gramatical, precedidos de elementos definidores.

A manutenção da referência pelo uso de expressões nominais, portanto, parece indicar que os aprendizes possuem melhor proficiência em português LE adicional, e este tem sido o recurso mais recorrente. Em menor proporção, observou-se o uso de termos encapsuladores (sumarizadores) por meio de anáforas indiretas e associativas que, embora menos recorrentes nos dados, revelam processamento textual de sujeitos proficientes na LE ao produzirem por escrito.

Em contrapartida, as reformulações sugerem que o sujeito-escritor antecipou uma dificuldade ("coisinhas informativas"), possivelmente porque determinado item lexical ainda não lhe era conhecido na LE ou ainda não fora ativado, embora possa estar presente no conhecimento sociocognitivo em sua L1 ou em outra LE que domina.

Os resultados sugerem que o desenvolvimento cognitivo e social dos sujeitos aprendendo uma outra língua, neste caso português LE-adicional, resulta das possibilidades de engajar-se em ações colaborativas de uso da linguagem. Em outras palavras, o envolvimento em ações colaborativas oportuniza aos sujeitos a reflexão do que se pode trazer para um texto e organizá-1o/produzi-lo, utilizando-se de estratégias (ilustradas neste artigo pelas estratégias de referenciação) para negociar os sentidos e situar-se 
como membro da comunidade sociointerativa de aprendizes e usuários da língua que estão aprendendo. Portanto, produzir por escrito em uma LEadicional requer que os sujeitos façam escolhas, dentre as que têm disponíveis e possíveis, de recursos referenciais e de conteúdo proposicional de acordo com as práticas sociais da comunidade de que participam e do conhecimento que têm de outras línguas e da LE-adicional em cena. Assim, as propriedades, as características e a organização textual da produção escrita variam de acordo com a proficiência, com o conhecimento de outras LEs e da LE-adicional que está aprendendo, além do interlocutor e do propósito.

Do ponto de vista do ensino, tarefas que propiciam a produção escrita de gêneros textuais diversos oportunizariam situações de uso da linguagem em que o sujeito poderia interagir, via gênero escrito, com diversas situações de uso da linguagem visto que os gêneros variam entre diversas esferas de uso da linguagem, interlocutores e propósitos. Tais tarefas representam um simples exemplo entre os inúmeros que promoveriam situações nas quais o sujeito poderia desenvolver-se cognitiva e socialmente pela construção e pela reconstrução de objetos de discurso.

\section{Referências}

BENTES, Ana C.; RIO, Vivian C. A construção conjunta da referência em uma entrevista semimonitorada com jovens universitários. In: $\mathrm{KOCH}$, Ingedore V.; MORATO, Edwiges M.; BENTES, Ana C. (Org.). Referenciação e discurso. São Paulo: Contexto, 2005. p. 265-292.

CONNOR, Ulla. Intercultural rhetoric research: beyond texts. Journal of English for Academic Purposes, v. 3, p. 291-304, 2004.

$\mathrm{KOCH}$, Ingedore V. A referenciação textual como estratégia cognitivointeracional. In: BARROS, Kazue S. M. (Org.). Produção textual: interação, processamento, variação. Natal: Editora da UFRN, 1999.

KOCH, Ingedore V. Introdução à Linguística Textual. São Paulo: Martins Fontes, 2004. 
LIMA, Maria L. C. Referenciação e investigação do processamento cognitivo: o exemplo do indefinido anafórico. In: $\mathrm{KOCH}$, Ingedore V.; MORATO, Edwiges M.; BENTES, Ana C. (Org.). Referenciação e discurso. São Paulo: Contexto, 2005. p. 197-218.

MILNER, Jean-Claude. Reflexões sobre a referência e a correferência. CAVALCANTE, Mônica M.; RODRIGUES, Bernardete B.; CIULLA, Alena (Org.). Referenciação. São Paulo: Contexto, 2003. p. 85-130.

MONDADA, Lorenza. A referência como trabalho interativo: a construção da visibilidade do detalhe anatômico durante uma operação cirúrgica. KOCH, Ingedore V.; MORATO, Edwiges M.; BENTES, Ana C. (Org.). Referenciação e discurso. São Paulo: Contexto, 2005. p. 11-32.

MONDADA, Lorenza; DUBOIS, Danièle. Construção dos objetos de discurso e categorização: uma abordagem dos processos de referenciação. CAVALCANTE, Mônica M.; RODRIGUES, Bernardete B.; CIULLA, Alena (Org.). Referenciação. São Paulo: Contexto, 2003. p. 17-52.

ROTTAVA, Lucia. Português como língua terceira (L3) ou língua estrangeira (LE) adicional: a voz do aprendiz indicando identidade. Em Aberto, Brasília, v. 22, n. 81, p. 81-98, ago. 2009.

ROTTAVA, Lucia; SILVA, Antônio M. Beliefs about Learning Portuguese as a Foreign Language - Multilingual Context. In: SILVA, Kleber A. (Org.). Crenças, discursos e linguagem. Vol. II. Campinas: Pontes Editores, 2011. p. 130-158.

ZAMPONI, Graziela. Estratégias de construção da referência no gênero de popularização da ciência. In: KOCH, Ingedore V.; MORATO, Edwiges M.; BENTES, Ana C. (Org.). Referenciação e discurso. São Paulo: Contexto, 2005. p. 169-196. 